\title{
Special issue introduction
}

\author{
Kate Hynes ${ }^{1} \cdot$ Ian Wooton ${ }^{2,3,4}$
}

Accepted: 23 January 2021 / Published online: 18 February 2021

( ) The Author(s), under exclusive licence to Springer Science+Business Media, LLC part of Springer Nature 2021

The papers in this special issue of International Tax and Public Finance were selected from the papers contributed to the International Workshop on 'Global Production, Taxes and Trade', hosted by Beijing University of Technology on 12-14 June 2019. The aim of this workshop was to bring together a group of scholars from across the world to share their expertise, discuss their research and exchange ideas on a broad range of topical issues in international trade and taxation. The group of experts taking part in this three-day workshop and roundtable discussion came from China, Hong Kong, Ireland, the UK, Australia, Germany, Belgium and Luxembourg.

Amongst the presentations at the workshop were a number of papers that were particularly suited to the readership of International Tax and Public Finance. As guest editors of this special issue, we are grateful to the authors of the five papers included in this symposium issue for submitting their work to the journal. We wish to thank the authors for their contributions, as well as the referees who helped to select the papers and provided insightful comments and suggestions on how to improve them. We also wish to thank the editors of International Tax and Public Finance for their helpful advice during different stages of the editorial process.

We are also grateful to the keynote speakers, panellists, presenters, discussants and participants in the workshop for their contributions in making this an exceptional and memorable event. We would especially like to thank Professors David Fitzpatrick and Wenying Wu for all of their support. Finally, we would like to recognise and thank the local organisers for their outstanding efforts in arranging the logistics of the workshop.

Kate Hynes

kate.hynes@dcu.ie

Ian Wooton

ian.wooton@strath.ac.uk

1 Dublin City University, Dublin, Ireland

2 University of Strathclyde, Glasgow, UK

3 CEPR, London, UK

4 CESifo, Munich, Germany 
Funding from Beijing University of Technology, University College Dublin and Beijing Dublin International College is very gratefully acknowledged.

Kate Hynes and Ian Wooton

Publisher's Note Springer Nature remains neutral with regard to jurisdictional claims in published maps and institutional affiliations. 